\title{
Matizes do discurso sobre avaliação na formação de professores da Educação Especial
}

\author{
Leandra Boer Possa* \\ Maria Inês Naujorks** \\ Grasiela Maria Silva Rios ${ }^{* * *}$
}

\section{Resumo}

Neste texto, discutimos os efeitos de sentido que diagnóstico e avaliação operam nos processos que subjetivam a atuação do professor da Educação Especial, considerando a naturalização destas práticas. Para problematizar, tomamos como materialidade de análise fragmentos dos relatórios de estágio produzidos por acadêmicas do Curso de Educação Especial da Universidade Federal de Santa Maria. Na análise, utilizamo-nos de conceitosmetodológicos ancorados nos estudos foucaultianos. Consideramos que não existem polos distintos e dialéticos de uma avaliação diagnóstica e clínica ou uma avaliação pedagógica em Educação Especial, pois o que há é uma tensão de forças que coexistem e marcam a atuação do professor deste campo: a anormalidade, o sujeito deficiente, sua identificação e a mediação de processos de ensino-aprendizagem que potencializem a chegada do deficiente o mais próximo da normalidade.

Palavras-chave: Avaliação; Diagnóstico; Professores da Educação Especial.

\footnotetext{
* Professora da Universidade Federal de Santa Maria. Doutoranda em Educação na Universidade Federal de Santa Maria (UFSM), Santa Maria, Rio Grande do Sul.

** Professora Doutora da Universidade Federal de Santa Maria, Santa Maria, Rio Grande do Sul.

*** Mestranda do Programa de Pós-graduação em Educaçao, Universidade Federal de Santa Maria (UFSM), Santa Maria, Rio Grande do Sul.
}

Revista Educação Especial | v. 25 | n. 44, | p. 465-482| set./dez. 2012

Santa Maria

Disponivel em: <http://www.ufsm.br/revistaeducacaoespecial> 


\title{
Tints of discourse on evaluation in training teachers of Special Education
}

\begin{abstract}
In this paper, we discuss the effects of meaning that operate in the diagnosis and evaluationprocesses that subjectivate the teacher performance of Special Education, considering the naturalization of these practices. To discuss, we take as materiality of analysis fragments ofinternship reports produced by the academics of Special Education Course at Universidade Federal de Santa Maria. In the analysis, we use the concepts and methodological anchored in Foucault studies. We consider that there are not distinct and dialectical poles of a clinicaland diagnostic evaluation or an assessment in Special Education, because there is a tensionof forces that coexist and characterize the performance of the teacher in this field: the abnormality, the persons with disability, the identification and mediation processes of teaching and learning that enhance the arrival of the persons with disability closer to normality.
\end{abstract}

Keywords: Evaluation; Diagnosis; Teachers of Special Education.

Para dar início a este texto, consideramos importante pontuar o que nos aproxima, enquanto pesquisadoras no campo da Educação Especial, para que assim possamos elaborar juntas esta produção textual. Referimosnos às temáticas que o envolvem, ou seja: os processos de avaliação que mobilizam a atuação do/a professor/a da Educação Especial e os processos de subjetivação deste profissional que toma como momento inicial de sua atuação o diagnóstico e/ou a avaliação, lançando um olhar investigativo, curioso e questionador sobre práticas avaliativas naturalizadas neste campo na contemporaneidade. A relação que buscaremos fazer entre diagnóstico e avaliação, no processo de formação e atuação do professor da Educação Especial, tem a ver com os efeitos de sentido que estas palavras produzem.

Em primeiro lugar, esta discussão foi mobilizada num evento do programa de pós-graduação em Educação, promovido pela linha de pesquisa em Educação Especial da UFSM, ocorrido em 2011, em que nós, juntamente com outras colegas, problematizávamos a invenção/produção de um discurso que marca como verdade a mudança paradigmática, pois a avaliação pedagógica teria substituído a avaliação clínica dando outro modo de atuação da Educação Especial na contemporaneidade. Teria tornando rarefeito o uso do diagnóstico que, por um tempo (para nós, muito presente), regimentava as práticas em Educação Especial a partir de um paradigma clínico-médico. 
Colocando esta verdade em suspeição, buscamos problematizar o possível "apagamento" do uso do diagnóstico (ainda necessário para que o aluno tenha acesso ao atendimento educacional especializado - AEE), a supremacia da avaliação pedagógica e tensionar a inexistência de diferença entre avaliação e diagnóstico.

Em segundo lugar, naquele evento, discutia-se uma ordem discursiva em que a atuação do professor de Educação Especial pautada pelo diagnóstico e, por conseguinte, num referencial clínico médico, já estaria sendo superada, pois uma produção positiva da área para o viés pedagógico havia compreendido o quanto o diagnóstico seria estigmatizante e excludente, agindo como um rótulo sobre o aluno.

Considerava-se ainda, que ao pautar/embasar a atuação do professor da Educação Especial para um modelo de avaliação pedagógica estaríamos não mais nomeando e classificando em função da anormalidade, da perda, do déficit, mas garantindo um tipo de intervenção que potencializaria a aprendizagem do aluno deficiente, pois ao voltar-se para a potencialidade humana, por meio do olhar atento do professor mediador, que avalia contínua e progressivamente, estar-se-ia respeitando os diferentes ritmos de aprendizagem dos sujeitos.

Ao colocarmos estas verdades em suspeição, não o fazemos com o intuito de estabelecer uma nova verdade, muito menos de indicar caminhos ou afirmar quais práticas são mais proveitosas. Dito de outro modo, não nos interessa pensarmos as questões relativas à avaliação e seus efeitos a partir de análises duais, pautadas em noções de certo/errado, melhor/pior, justiça/injustiça. Da mesma forma, não pensávamos que durante aquele evento iríamos esgotar o debate e tampouco consideramos que neste texto o faremos. Mas, foi buscando ocuparmo-nos dele que nos propusemos pensar nos discursos em torno do diagnóstico e da avaliação, como efeitos de diferentes tons para a atuação dos professores da Educação Especial que, no entanto, passam pelo mesmo matiz.

Assim, tomamos a palavra matiz com o sentido de identificar as propriedades da cor, como diagnóstico e avaliação são propriedades da atuação do professor da Educação Especial. Tanto cor como atuação - seja pela avaliação pedagógica ou pelo diagnóstico - podem ter tonalidades diferentes, pois é pelas tonalidades que se torna possível classificar e distinguir aquilo que continua sendo cor, aquilo que continua sendo atuação do professor de Educação Especial. 
Diagnóstico e avaliação, diferentes tons de um matiz e a atuação do professor da Educação Especial constituem-se naquilo que nos propusemos a pensar neste texto. Para tanto, tomamos como materialidade de análise os relatórios de estágio produzidos pelas Educadoras Especiais em formação, trazendo recortes, fragmentos que apontam o sentido do diagnóstico e da avaliação na atuação dessas professoras. Com isso, buscaremos identificar o tom e o matiz que o diagnóstico e a avaliação podem dar às suas práticas. Para a análise dos fragmentos textuais dos relatórios das práticas de estágio das acadêmicas do Curso de Educação Especial da Universidade Federal de Santa Maria, tomamos como ferramentas analíticas conceitos ancorados nos estudos foucautianos.

Entender os discursos de diagnóstico e avaliação e observar o que possibilitou ser construído torna-se indispensável para que possamos conhecer os regimes de verdade que se naturalizam em torno do que se entende por paradigmas de atuação da Educação Especial. Consideramos que não existem polos distintos e dialéticos de uma Educação Especial clínica e uma Educação Especial pedagógica, como se a segunda manifestasse uma evolução natural à superação da primeira. O que pode haver, sim, é uma tensão de forças que coexistem, marcando o entre-lugar objeto de estudo da atuação do professor da Educação Especial: a anormalidade, a deficiência, o sujeito deficiente, sua identificação e, por fim, a mediação de processos de ensino-aprendizagem que potencializem a chegada do deficiente o mais próximo da normalidade ou da igualdade de condições que lhes permita viver em sociedade como os outros humanos. Esta constatação não permite que lidemos neste binômio.

Quais saberes mobilizam diagnóstico e avaliação? Como olhar para estes discursos e entender as relações de força que se tecem, os mecanismos e dispositivos pelos quais o poder opera? Como identificar nos discursos sobre diagnóstico e avaliação o rompimento com saberes estabelecidos, as marcas e recorrências que indiquem a emergência, o surgimento de outras verdades, outros saberes?

Foucault nos mostra que a cada época correspondem modelos predominantes de discurso, de uma tessitura de redes discursivas que indicam o que dizer sobre as coisas e sobre os objetos, de forma que "não se pode falar de qualquer coisa em qualquer época" (Foucault, in BUJES, 2001, p.24). Essas diferentes redes de sentido nos atravessam, de forma que o que entendemos como natural, é constituído, construído, inventado nas e pelas redes de saber e poder que, compartilhadas no tecido social, tornamse, então, regimes de verdade. 
Nas palavras do filósofo, "cada sociedade tem seu regime de verdade, sua política geral de verdade, tipos de discurso que aceita e faz funcionar como verdadeiros [...] os meios pelos quais cada um deles é sancionado". (1993, p. 12). Estes regimes de verdade são constituídos nas e pelas relações de poder.

Consideramos então, de início, que os saberes, os discursos sobre diagnóstico ou avaliação, de que se ocupam os professores da Educação Especial, não servem para externalizar pensamentos ou para referenciar uma realidade da deficiência ou do deficiente, como algo que esteve sempre aí, atemporal, mas sim para inventar uma deficiência, um "outro deficiente" e uma atuação para o professor da Educação Especial. São práticas discursivas que obedecem a regras e que se estruturam, as quais têm relação com outros discursos que articulados produzem saberes e naturalizam verdades, que se potencializam como mais verdadeiras em determinadas épocas e em decorrência de determinados acontecimentos.

São acontecimentos econômicos, políticos e culturais, os quais produzem outros discursos que tornam possível inventar diferentes paradigmas para a Educação Especial e, com isso, tonalidades para práticas de diagnóstico ou de avaliação.

A invenção de paradigmas para a Educação Especial segregacionista ou inclusivista - como polos dialéticos que incidem em excluir ou incluir, também geram modelos de identificação, classificação e atuação que se situam: de um lado como modelo segregacionista calcado no diagnóstico e, por outro, o modelo de avaliação pedagógica como possibilidade de identificação das potencialidades de aprendizagem e, por isso, há uma sensação de apagamento da deficiência. Por um lado, o diagnóstico como estigmatizante e, por outro, a avaliação pedagógica como construção da aprendizagem.

Essa simplificação binômia aparece em alguns fragmentos colhidos nos Relatórios de atuação do professor da Educação Especial, a exemplo:

[...] Não nos deteremos a pensar em aprendizagens baseados em diagnósticos, pois consideramos nossos alunos com dificuldade na aprendizagem e assim vamos definir um trabalho para cada nível desta dificuldade. Fica claro que seus diagnósticos são diferenciados e ainda indefinidos para alguns, portanto não cabe a nós rotular algum aluno, e muito menos definir algum tipo de deficiência. Nosso intuito é pedagógico, portanto consideramos suas potencialidades em primeira instância, para depois pensarmos nas suas deficiências. 
[...] Conceber o aluno para após elaborar estratégias de ensino, são fatores indispensáveis para a nossa prática. (PEREIRA, 12/2004, p. 17)

O diagnóstico como nomeação da anormalidade e a avaliação pedagógica como superação dela aparecem como paradigmas de atuação. No entanto, há de se ter prudência com os paradigmas, assim tão fixos e envoltos por uma rede de discursos de transformação como condição de ser melhor, superior e mais verdadeiro. Veiga-Neto corrobora com esta ideia, ao indicar que há de se ter cuidado com os paradigmas, implicando ter-se cuidado com discursos que "pensam se colocar numa posição acima para poderem se referir a - e tematizar sobre - outros a partir de um presumido metaparadigma, que se pretende mais abrangente e, por isso, melhor" (2007, p. 35). O autor ainda coloca que é interessante usarmos paradigma em seu sentido fraco, aquele que indica de onde falamos, de uma visão de mundo a qual atribuímos um determinado significado e não outro, já que uma mesma palavra pode assumir sentidos diferentes de teoria para teoria dentro de um mesmo paradigma.

Aceitando o sentido fraco de paradigma, pode-se dizer que - queiramos ou não, saibamos ou não - sempre nos localizamos num paradigma, a partir do qual constituímos nossos entendimentos sobre o mundo e construímos nossas representações. [...] Não estamos falando sobre "coisas" que já estavam simplesmente aí, a espera daquilo que temos a dizer sobre elas. O que estamos fazendo é entrando em uma rede discursiva precedente, que, antes, já havia colocado-as no mundo na medida em que havia atribuído determinados sentidos a elas. (2007, p. 43)

Há de se ter cuidado com esta lógica paradigmática, pois se as verdades são produzidas pelos acontecimentos e estes podem negar as verdades que já existiam, torna-se importante considerar como o discurso da avaliação pedagógica substitui ou torna rarefeito e recortado o discurso do diagnóstico, já que este não desaparece, mas é colocado em segundo plano, em suspensão? Quais arranjos na ordem do saber produzido na área da Educação Especial permitem hoje dizer sobre a avaliação pedagógica como superior a ordem do diagnóstico? Como se constroem as condições para que este discurso da avaliação substitua o de diagnóstico? Como o discurso da avaliação toma regularidade e fixa as suas fronteiras? Como acontece o apagamento - o não dito, o segundo plano - do discurso do diagnóstico? 
Estas questões nos levam a pensar sobre a área da Educação Especial como uma invenção que se torna possível graças ao arranjo de saberes médicos, psicológicos e pedagógicos. É a possibilidade de estabelecer uma verdade para conhecer sobre aquele que não era normal, que destoava do conjunto, aquele que se apresentava como enigma a ser 'desvelado' e, por fim, curado ou (re)habilitado à vida humana, que se torna possível falar e justificar esta área de estudo e de atuação sendo, entre o final do século XIX e o início do século XX, nominado Educação Especial.

É na perspectiva de uma educação capaz de educar a todos, profetizada nos séculos XVII e XVIII, pedagogia racional-iluministahumanistas, legitimada pela ciência racional moderna, que se tem as condições de possibilidade da emergência da Educação Especial, ou seja, uma das tonalidades desse matiz, como afirma Lunardi:

Com [...] a consolidação do estado moderno, passase a difundir, paulatinamente, a noção de normalidade, pretendida pela então visão legitimadora da ciência, e promove-se uma higienização da anormalidade, procedendo-se, assim, a uma enclausuramento da anormalidade com fins de reabilitação e de cura. Portanto, a partir do racionalismo moderno, intensificase a atenção ao individuo, ou seja, há uma regulação do tempo e do espaço a fim de ritualizar e formalizar condutas e procedimentos normativos. Assim, são nesses espaços que os procedimentos de classificação e ordenação das condutas dos sujeitos se edificam e se constituem na "base da taxonomia social que distingue os seres humanos" (FOUCAULT, 1992, p. 134). Para este autor, o cartesianismo inaugura a comparação racional e meticulosa daquilo que deveria cosubstanciar e organizar o conhecimento. Neste sentido poderíamos pensar que a episteme que caracteriza os séculos XVII e XVIII constitui uma matriz de emergência da consolidação de instituições reguladoras - entre elas, a escola - e para o estudo da Educação Especial. (2003, p. 86)

Tomamos como outra tonalidade desse matiz o saber médico. Apoiamo-nos no pensamento de Lunardi, visto que a autora demonstra que o mesmo, nas instituições educacionais do deficiente, tem o papel fundamental de subsidiar com suas técnicas um olhar clínico sobre o corpo e sobre a alma apontando caminhos terapêuticos. É o estudo etiológico da deficiência, o olhar atento para o indivíduo e sua conduta, junto com regimes de verdade que dizem sobre a normalidade e a anormalidade que se torna possível classificar, distinguir e localizar no contexto educativo a clientela da Educação Especial, visto que 
São essas diferenças que caracterizam as pessoas 'especiais' que devem ser cientificamente diagnosticadas com a finalidade 'não tanto de curar ou corrigir o déficit [...], mas de adaptar as intervenções às particularidades de tal déficit. (MARTINEZ; SUNÉZ, 1999, p. 46) (LUNARDI, 2003, p. 96)

Nosso matiz também contempla a tonalidade da Psicologia como ciência que estuda as condutas de forma que ela entra no arranjo da constituição da Educação Especial, pois ao estabelecer a visibilidade da conduta normal se torna capaz de descrever o anormal, por meio de

\begin{abstract}
Um olhar voltado para o diagnóstico individual, para a mediação da conduta humana, permite a elaboração de um conjunto de instrumentos e técnicas ancorados e respaldados pelos saberes da estatística. Com base em critérios específicos, os indivíduos foram sendo normalizados em relação a agregados estatísticos, os quais mantém monitorados e supervisionados o desenvolvimento e o crescimento das populações em risco. (LUNARDI, 2003, p. 97)
\end{abstract}

Nessas três tonalidades constituidoras da Educação Especial, percebemos um matiz comum que vai permear tanto a invenção desta área como a continuidade dela, ou seja, os movimento que a inventam até hoje.

O primeiro tom deste matiz é a produção de um sujeito e a atenção sobre o indivíduo e sua conduta a partir da regularização de um tempo e espaço para que ele conduza a si mesmo numa relação com os outros; assim, a Educação Especial é inventada como área de estudo atuando num contexto institucional que tem como base a ordenação e classificação das condutas. O segundo tom do matiz é a identificação da anormalidade bem como sua caracterização, para que a deficiência possa ser conhecida e descrita, para que a pessoa deficiente possa ser localizada e se possa distinguir dela um modelo, um plano de correção que para tanto precisa ser desenvolvido para o indivíduo com seus déficits. $\mathrm{E}$, o terceiro tom deste matiz está em conhecer muito o indivíduo, produzir um diagnóstico quantitativo e qualitativo de suas condutas, manter o indivíduo sobre o monitoramento de alguém que conhece muito sobre o crescimento, desenvolvimento e aprendizagem para que estes expertises possam elaborar um plano de intervenção que aproxime a anormalidade da normalidade.

Diante deste matiz com arranjos de tonalidades, temos a Educação Especial sendo inventada e no arranjo desta invenção podemos apontar que diagnóstico como identificação da deficiência e avaliação como 
monitoramento e intervenção pedagógica, em que os dois são objetos de um discurso que, ao fim e ao cabo, mantêm um mesmo objetivo para a atuação do professor da Educação Especial, qual seja: a identificação da anormalidade, a normalização e o controle.

Tanto diagnóstico como avaliação colocam em funcionamento um tipo de saber-poder que circula, que é exercido em redes; que inventa e submete o indivíduo deficiente a um saber-poder que é exercido pelo professor da Educação Especial e por outros profissionais da área da saúde; um saber-poder que transita pelo indivíduo que ele constituiu (FOUCAULT, 1999, p. 35).

É a eficiência da classificação, ordenação e monitoramento tanto no diagnóstico como na avaliação dos indivíduos que colocam em funcionamento operadores discursivos e práticas não-discursivas, "métodos de observação, técnicas de registro, procedimentos de investigação e de pesquisa" (FOUCAULT, 1999, p. 40) que permitem o trabalho do professor da Educação Especial e o constante processo de subjetivação que tais métodos, técnicas e procedimentos serem "instrumentos efetivos de formação e de acúmulo de saber" (ibidem), que como expertises, são capazes de produzir.

Neste sentido, podemos agora nos ocupar de alguns fragmentos coletados nos relatórios de estágios de acadêmicos do curso de Educação Especial da Universidade Federal de Santa Maria para que possamos perceber como estes são subjetivados por este matiz discursivo sobre diagnóstico e avaliação que a Educação Especial carrega.

Na maioria dos fragmentos, o discurso em relação ao sujeito da deficiência se caracteriza pela indicação do que lhe falta, daquilo que o distancia do normal, daquilo que o inferioriza.

Possui perda auditiva sensorial. [...] Carina apresenta o desenvolvimento de uma criança com idade inferior a sua. (NICOLOSO, Relatório 09/1994)

Observa-se um atraso no desenvolvimento motor [...] não possui noção de tempo, possui dificuldades na linguagem expressiva [...] não identifica cores, formas, quantidades, letras. (LEMES, Relatório 13/1994)

'M' não tem uma postura tônico-postural adequada, ele sente dificuldades em perceber as coisas do mundo e em relação aos outros. Aárea motora está comprometida [...] seus movimentos não são sincronizados e seguros [...] demonstra um grande desajustamento corporal [...] a agitação motora intensa produz falta de concentração. (MEDEIROS, Relatório 10/1995, s/p) 
Podemos observar que estes fragmentos encerram certa narrativa que faz a produção do sujeito com deficiência. Ao descrever sua conduta, faz-se a descrição de quem ele é, de como está no mundo. Tem-se a preocupação em dizer, classificar, dar um nome para estabelecer como a falta, as dificuldades e os atrasos caracterizam o desvio da normalidade. Neste sentido, podemos perceber os próximos fragmentos:

[...] os alunos da turma de pré-alfabetização [...], consiste em dois alunos, um com Síndrome de Down (13 anos) e outro possível diagnóstico de deficiência mental (12 anos). Os alunos encontram-se no período préoperatório, em que o pensamento intuitivo é egocêntrico, o que impossibilita a execução das operações mentais de classificação, seriação, conservação e generalização das aprendizagens. (DUARTE, 08/2002, p. 02)

[...] com 7 anos tem fala infantilizada e de difícil compreensão. Segundo o parecer do aluno este possui atraso no seu desenvolvimento [...] com 13 anos, possui diagnóstico de deficiência mental [...] Comunica-se pouco, [...] Sua compreensão é bastante limitada [...] com 16 anos, tem diagnóstico de Paralisia Cerebral. Possui atraso em seu desenvolvimento cognitivo, dificuldade de fala, na escrita e no raciocínio lógico-matemático [...]. (FORTES, 02/2007, p. 10-20)

[...] o aluno V. é uma criança tímida, apresenta certa dificuldade na interação [...] CA apresentava insegurança para realizar as tarefas [...] a aluna CR [...] é bastante competitiva [...] O aluno A apresentava inúmeras dificuldades para realizar as tarefas, [...] distraído e quando era repreendido começava a chorar. [...] o aluno NA chegava sempre cansado, com pouca motivação para fazer as atividades em decorrência do uso de remédios para controlar a hiperatividade [...]. (MELARA; LACERDA, 03/2008, p. 08)

Parece evidente, no contexto destes fragmentos discursivos, o valor dado ao diagnóstico como identificação, caracterização e descrição da falta que nomeia a anormalidade, os déficits.

Num segundo agrupamento de fragmentos, podemos observar que conhecer profundamente o sujeito, bem como tudo aquilo que se relaciona com ele e suas condutas possíveis, constitui-se num dos papeis fundamentais da atuação do professor da Educação Especial.

Cabe ao educador a tarefa de se tornar um observador constante, que deve avaliar as atividades dos alunos 
perante as atividades propostas, para descobrir o momento de prosseguir em busca de um novo conhecimento ou até meso insistir no que se tem como objetivo. (FREITAS, Relatório 19/98)

[...] observeialgumas aulas a fim deanalisar o desempenho dos alunos na classe quanto à aprendizagem, linguagem, comportamento, fatores psicomotores e cognitivos bem como fatores sócio-afetivos e ambientais, o que é fundamental para desenvolver um trabalho coerente com a realidade e adequado para cada aluno consiga desenvolver seu potencial. (DEBUS, 01/2007, p. 06)

Quanto à escola, devem ser feitos anamneses e diagnósticos por uma equipe multidisciplinar para que se saiba qual a melhor opção para a criança paralisada cerebral. (GUARESCHI, 02/2002, p. 09)

A palavra diagnóstico diz respeito ao conhecimento efetivo ou a confirmação sobre algo, envolvendo tudo aquilo que podemos entender, esmiuçar e conhecer por meio do exame e da descrição minuciosa, um certo objeto de observação. Aquilo que o sentido de diagnóstico tem em seu significado, então, envolve os processos que subjetiva a atuação do professor da Educação Especial.

Não haverá progresso na Educação Especial sem diagnóstico, identificação precoce e participação ativa dos pais, pois o englobamento destes minimizará os efeitos cumulativos de problemas de desenvolvimento da criança surda. (BRAGA, Relatório 23/96)

Colocar em primeiro plano o sujeito que aprende, procurando conhecer melhor cada criança com a qual se trabalha, suas características, estágios de evolução na qual se situa suas capacidades e condições de ser ativo, [...] para não subestimá-lo e para saber provocar o seu desenvolvimento. (MAURER, Relatório 04/95)

Éfundamental queoprofessor conheçaodesenvolvimento humano e atualize-se; além de conhecer o meio atual onde o aluno vive, com quem e como ele convive neste meio; conhecer o meio social, cultural e físico; além da reciprocidade e relações do aluno com o seu meio. (MACHADO, 17/1999, p. 22)

Identificar, descrever, por isso conhecer produzir um diagnóstico para que se possa dele produzir um planejamento educativo, que poderá ser monitorado e avaliado constantemente, constituem-se do discurso que envolve a atuação do professor da Educação Especial. Este é o conjunto de fragmentos que compõem o terceiro bloco a seguir: 
Conclui-se, que é de fundamental importância conhecermos bem o desenvolvimento global do nosso aluno para melhor montarmos uma proposta e trabalharmos com ele, não podendo de maneira alguma, desprezar esse conhecimento, pois se fizermos isto, estaremos correndo o risco de estar fazendo de conta que contribuímos para a educação dos nossos alunos portadores de necessidades especiais. (PEREIRA, Relatório 32/96)

[...] é de fundamental importância conhecermos bem o desenvolvimento global do aluno para montarmos uma proposta e trabalharmos com ele; pois se desprezarmos estes conhecimentos, estaremos correndo um risco de estar fazendo de conta que contribuímos para a educação dos mesmos. (PEREIRA, Relatório 32/96)

Esta prática pretendeu orientar e avaliar os educandos no sentido de sempre alcançarem seus conhecimentos. Avaliá-los é necessário para melhor direcionar o trabalho pedagógico visando sempre a oportunizar o crescimento do aluno, oferecendo-lhe o ambiente mais adequado possível. Como base, utilizou-se a aprendizagem construída no decorrer do curso, com a orientação dos professores e principalmente muita dedicação. (FERNANDES, Relatório 40/97)

Observa-se aqui que o diagnóstico inicial é tomado como descoberta que possibilitará abrir caminhos, conhecer bem para que se possa produzir um plano de correção, uma intervenção pedagógica que, prevista num regime de verdade, é produzida e colocada em operação pela atuação do professor da Educação Especial. Uma intervenção pedagógica que se deduz da avaliação constantemente dos avanços ou dos fracassos, tendo em vista a normalização dos sujeitos da deficiência. Esta ideia fica mais explicita nos fragmentos a seguir:

Sem a LS o surdo não terá subsídios para recorrer ao planejamento de solução de problemas; Não conseguirá superar a ação impulsiva; Não irá adquirir independência da situação visual concreta; Não controlará seu próprio comportamento e ambiente; $E$, finalmente, não se socializará adequadamente. (SOARES, 10/2004, p. 09)

[...] é preciso considerar que a criança que não aprende é sempre recuperável, embora varie o tempo necessário conforme o ritmo de cada um dentro dos limites de seu desenvolvimento mental e grau de maturidade. Mas, antes de corrigir os atrasos na aprendizagem, procurou- 
se criar fundamentalmente nos alunos um interesse de relação afetiva entre professor-aluno, aluno-aluno, por considerar que o vínculo afetivo é um dos principais caminhos para uma melhora na aprendizagem. (NICOLOSO, 16/1998, p. 109)

[...] observações realizadas e classe de ensino comum verifica-se a necessidade de um atendimento diferenciado com estes alunos, trabalhando suas reais dificuldades, a fim de saná-las ou amenizá-las. (FLORES, 10/2003, p. 02)

Ainda, a ideia de monitoramento, acompanhamento, vigilância sobre o desenvolvimento e aprendizagem do sujeito da falta continuam a produzi-lo. A necessidade de estabelecer sempre o controle, para que nada fuja do olhar do expertise, é o modelo de atuação que subjetiva o professor da Educação Especial, isso pode ser obsevado no fragmento a seguir:

Diante de todas nossas intervenções, buscamos entender como o aluno assimila tudo o que lhe é apresentado durante seu aprendizado na rotina escolar, o que nos provocou algumas inquietações pelo fato de ele parecer estar sempre distraído, de não conseguirmos fixar sua atenção por muito tempo e ainda assim o aluno possuir conhecimento de várias coisas, as quais não conseguimos entender como ele aprendeu, de que forma internaliza seus aprendizados. (MACHADO; BRAZ, 07/2009, p. 19)

O olhar, o exame, a observação, o monitoramento e a experimentação são práticas não discursivas que produzem os discursos de diagnóstico e avaliação, elas têm uma mesma referência, pois têm o poder de estabelecer uma verdade, de inventar uma verdade sobre o sujeito da deficiência e uma forma de atuação do professor da Educação Especial.

Tornando o indivíduo visível, fragilizado e susceptível a uma circunstância, a uma necessidade educacional, social e cultural, produz-se um sujeito pedagógico, com vista a igualá-lo e normalizá-lo. Aquilo que se descreve como necessidade do sujeito é, portanto, um discurso de referência pedagógica, que tem a função de produzir um sujeito que precisa ser educado.

Para Foucault (1987), o exame e, por isso, o diagnóstico e a avaliação, fazem cada um dos alunos, sujeitos da falta/deficiência, tornaremse um caso. Para a Educação Especial, a individualidade é algo pertinente 
e relevante, pois a identificação e o monitoramento da individualidade fixam, por meio do saber-poder desta área, o lugar das diferenças individuais, da diversidade, conceitos tão caros para a Educação Especial em qualquer condição de possibilidade histórica, mas principalmente no momento em que passamos a ancorá-la na perspectiva inclusiva.

O caso individual faz parte do conjunto estatístico dos casos e isso em cada época histórica da Educação Especial, organizam-se, numa ordem, novas divisões e classificações e novas formas de atuação, sejam nas instituições especializadas ou nas atuais salas de atendimentos especializados e escolas inclusivas. Isso pode ser identificado no fragmento abaixo:

Primeiramente viu-se a necessidade de constituir novos grupos nos quais as características cognitivas pudessem ter mais afinidades para que os estímulos fossem mais eficazes. Dividiu-se então o grande grupo em atendimentos com grupos menores e com os níveis de cognição mais próximos, levando em consideração as combinações e disponibilidade dos alunos virem ao atendimento. Uma das alternativas foi elaborar uma proposta de ação que suprisse as necessidades de aprendizagem de cada aluno, considerando o fato de que alfabetizar não se define em apenas ensinar a ler e escrever, deve ser levado em conta os aspectos sócioafetivos e psicomotores para, só assim, iniciar o processo de alfabetização. (PEREIRA, 12/2004, p. 05)

Poderíamos avançar mais, mas, como dissemos no início, esta não é uma discussão a ser feita por três cabeças, procuramos parceiros/as para continuar a pensar nas questões que dinamizaram este texto: como o discurso da avaliação pedagógica substitui ou torna rarefeito e recortado o discurso do diagnóstico, já que este não desaparece, mas é colocado em segundo plano, em suspensão? Quais arranjos na ordem do saber produzido na área da Educação Especial permitem hoje dizer sobre a avaliação pedagógica como superior a ordem do diagnóstico? Como se constroem as condições para que este discurso da avaliação substitua o de diagnóstico? Como o discurso da avaliação toma regularidade e fixa as suas fronteiras? Como acontece o apagamento - o não dito, o segundo plano - do discurso do diagnóstico? 
É pensando neste contexto de discussão que não podemos abrir mão de problematizar estas questões, pois elas estão subjetivando um modo de atuação do professor da Educação Especial, que em formação, nos últimos anos, vem tomando para si o regime de verdade da Educação Especial e da Escola Inclusiva. Este professor que pode estar naturalizando o pedagógico da avaliação e apagando ingenuamente aquilo que ela tem de diagnóstica.

\section{Referências}

BRAGA, L. F. Relatório de estágio supervisionado. 1996. Relatório 23 (Curso de Educação Especial) - Universidade Federal de Santa Maria, 1996.

CASTRO, E. Vocabulário de Foucault - um percurso pelos seus temas, conceitos e autores. Belo Horizonte: Autêntica, 2009.

COSTA, M. V. Velhos temas, novos problemas - a arte de perguntar em tempos pós-modernos. In: COSTA, M. V; BUJES, M. I. E. (Orgs.). Caminhos investigativos III: riscos e possibilidades de pesquisar nas fronteiras. Rio de Janeiro: DP\&A Editora, 2005, 199-214.

DEBACCO, M. S. Realização docente: mecanismos de sujeição e gratificação. Porto Alegre: PUC/RS, 2009, 98p. Tese (Doutorado em Educação) - Programa de Pós-Graduação em Educação, Pontifícia Católica do Rio Grande do Sul, Porto Alegre, 2009.

DEBUS, Clarissa dos Santos. Relatório de Estágio Supervisionado. 2007. Relatório 01 (Curso de Educação Especial) - Universidade Federal de Santa Maria, 2007.

DOHERTY, R. Uma política educacional criticamente formativa: Foucault, discurso e governamentalidade. In: PETERS, M; BESLEY, T. (Orgs.). Por que Foucault? Novas diretrizes para a pesquisa educacional. Porto Alegre: Artmed, 2008, p. 2001-212.

FERNANDES, Adriana. Relatório de estágio supervisionado. 1997. Relatório 40 (Curso de Educação Especial) - Universidade Federal de Santa Maria, 1997.

FISCHER, R. M. Verdades em suspenso: Foucault e os perigos a enfrentar. In: COSTA, M. V. (Org.). Caminhos investigativos II: outros modos de pensar e fazer a pesquisa em educação. Rio de Janeiro: Lamparina Editora, 2007, p. 49-70.

Revista Educação Especial | v. 25 | n. 44, | p. 465-482| set./dez. 2012

Santa Maria

Disponível em: <http://www.ufsm.br/revistaeducacaoespecial> 
FLORES, J. de M. Relatório de estágio supervisionado. 2003. Relatório 10 (Curso de Educação Especial) - Universidade Federal de Santa Maria, 2003.

FONSECA, M. A. Michel Foucault e a constituição do sujeito moderno. São Paulo: EDUC, 1995.

FOUCAULT, M. A arqueologia do saber. Rio de Janeiro: Forense Universitária, 2005.

Microfísica do poder. Rio de Janeiro: Edições Graal, 1979.

Os Anormais: cursos curso dado no Collège de France (1974-1975). São Paulo: Martins Fontes, 2010. 1987.

Vigiar e punir: nascimento da prisão. Petrópolis: Editora Vozes,

FREITAS, L. M. Relatório de estágio supervisionado. 1998. Relatório 19 (Curso de Educação Especial) - Universidade Federal de Santa Maria, 1998.

GADELHA, S. Biopolítica, governamentalidade e educação: introdução e conexão a partir de Michel Foucault, Belo Horizonte: Autêntica, 2009.

GUARESCHI, T. Relatório de estágio supervisionado. 2002. Relatório 02 (Curso de Educação Especial) - Universidade Federal de Santa Maria, 2002.

GUIDOLIN, C. T. Relatório de estágio supervisionado. 1995. Relatório 14 (Curso de Educação Especial) - Universidade Federal de Santa Maria, 1995.

LORENZINI, F. Relatório de Estágio Supervisionado. 1995. Relatório 32 (Curso de Educação Especial) - Universidade Federal de Santa Maria, 1995.

LUNARDI, M. L. A produção da anormalidade surda nos discursos da Educação Especial. Porto Alegre: UFRGS, 2003, 200p. Tese (Doutorado em Educação) - Programa de Pós-Graduação em Educação, Faculdade de Educação, Universidade Federal do Rio Grande do Sul, Porto Alegre, 2003.

MACHADO, D. S. Relatório de Estágio Supervisionado. 1999. Relatório 17 (Curso de Educação Especial) - Universidade Federal de Santa Maria, 1999.

MACHADO, E. D.; BRAZ, L. da S. Relatório de estágio supervisionado. 2009. Relatório 07 (Curso de Educação Especial) - Universidade Federal de Santa Maria, 2009. 
MAURER, L. Relatório de estágio supervisionado. 1995. Relatório 07 (Curso de Educação Especial) - Universidade Federal de Santa Maria, 1995.

NICOLOSO, Â. M. B. Relatório de estágio supervisionado. 1998. Relatório 16 (Curso de Educação Especial) - Universidade Federal de Santa Maria, 1998.

PEREIRA, A. P. Relatório de estágio supervisionado. 2004. Relatório 12 (Curso de Educação Especial) - Universidade Federal de Santa Maria, 2004.

PEREIRA, M. F. Relatório de estágio supervisionado. 1996. Relatório 32 (Curso de Educação Especial) - Universidade Federal de Santa Maria, 1996.

PETERS, M. Pesquisa educacional: os 'jogos da verdade' e a ética da subjetividade. In: PETERS, M; BESLEY, T. (Orgs.). Por que Foucault? Novas diretrizes para a pesquisa educacional. Porto Alegre: Artmed, 2008, p. $189-200$.

SOARES, Nádia Bolsan. Relatório de estágio supervisionado. 2004. Relatório 10 (Curso de Educação Especial) - Universidade Federal de Santa Maria, 2004.

SOMMER, L. H. Tomando palavras como lentes. In: COSTA, M. V; BUJES, M. I. E. (Orgs.). Caminhos Investigativos III: riscos e possibilidades de pesquisar nas fronteiras. Rio de Janeiro: DP\&A, 2005, p. 69-84.

VEIGA-NETO, A. Coisas do governo... In: RAGO, M; ORLANDI, L. B. L; VEIGA-NETO, A. (Orgs.). Imagens de Foucault e Deleuze: ressonâncias nietzschianas. Rio de Janeiro: DP\&A, 2005, p. 13-34.

. A. Olhares. In: COSTA, M. V. (Org.). Caminhos investigativos I: novos olhares na pesquisa em educação. Rio de Janeiro: Lamparina, 2007, p. 23-38.

VEIGA-NETO, A. Paradigmas? Cuidado com eles! In: COSTA, M. V. (Org.). Caminhos investigativos II: outros modos de pensar e fazer a pesquisa em educação. Rio de Janeiro: Lamparina, 2007, p. 35-48. 
Leandra Boer Possa - Maria Inês Naujorks - Grasiela Maria Silva Rios

\section{Correspondência}

Leandra Boer Possa - Rua Leovegildo Leal de Moares, 275. - Camobi CEP: 97110-820, Santa Maria, Rio Grande do Sul.

E-mail: leandrabp@gmail.com -minau@uol.com.br - grasielarios@gmail.com

Recebido em 16 de julho de 2012

Aprovado em 17 de outubro de 2012

Revista Educação Especial | v. 25 | n. 44, | p. 465-482 | set./dez. 2012 Santa Maria Disponível em: <http://www.ufsm.br/revistaeducacaoespecial> 